\title{
Revisión Anatómica del Músculo Bíceps Femoral del Canino
}

\author{
Anatomical Review of Canine Biceps Femoris Muscle
}

\author{
C. A. Arzone; C. J. Blanco; P. Genoud; F. C. Pellegrino; G. Sánchez \& R. J. Vidal Figueredo
}

\begin{abstract}
ARZONE, C. A.; BLANCO, C. J.; GENOUD, P.; PELLEGRINO, F. C.; SÁNCHEZ, G. \& VIDAL FIGUEREDO, R. J. Revisión anatómica del músculo bíceps femoral del canino. Int. J. Morphol., 28(4):1147-1149, 2010.

RESUMEN: El músculo bíceps femoral (BF) desempeña un rol fundamental en la biomecánica del miembro pelviano de los caninos, actuando en la flexoextensión de la articulación femorotibiorotuliana y la abducción del miembro. La evaluación correcta de su función es importante en la clínica veterinaria. Existen puntos controversiales entre los autores consultados acerca de la morfología de este músculo. El presente estudio tiene como objetivo discutir las distintas descripciones, reparando en las inserciones, la estructura e inervación del músculo. Se han realizado las disecciones bilaterales en 12 animales. La conservación de las piezas se realizó por inmersión en piletas, con una dilución de formol al $10 \%$ y ácido fenico al $4 \%$ en agua. Se utilizaron diferentes técnicas de abordaje al músculo en cuestión, para obtener distintas observaciones de las estructuras. Se halló que el músculo BF se origina por medio de dos cabezas, como queda implícito en su denominación, una cabeza craneal, más voluminosa y una cabeza caudal más pequeña. La primera originada en el ligamento sacrotuberal y en la superficie lateral de la tuberosidad isquiática. La cabeza caudal, se origina de la tuberosidad isquiática. Estas partes a pesar de hallarse estrechamente unidas se individualizan a nivel de los vientres musculares por medio de una delgada lámina de tejido conectivo que se extiende hasta el tercio distal del músculo. Respecto a la inervación, no se encontraron ramas del nervio glúteo caudal que inerven las partes al músculo.
\end{abstract}

PALABRAS CLAVE: Músculo bíceps femoral; Canino; Estructura anatómica.

\section{INTRODUCCIÓN}

El músculo bíceps femoral (BF) desempeña un rol fundamental en la biomecánica del miembro pelviano de los caninos, actuando en la flexoextensión de la articulación femorotibiopatelar y la abducción del miembro. La evaluación correcta de su función es importante en la clínica veterinaria. Existen puntos controversiales entre los autores consultados acerca de la morfología de este músculo (Schwarze et al., 1970; Dyce et al., 1999). El presente estudio tiene como objetivo discutir las distintas descripciones, reparando en las inserciones, la estructura e inervación del músculo.

\section{MATERIAL Y MÉTODO}

Trabajamos sobre preparaciones cadavéricas de 12 caninos macho de tamaño mediano, 8 beagles y el resto mestizos. Los mismos fueron fijados por inyección intravascular y posterior inmersión en una solución fijadora compuesta por formaldehido al $10 \%$ y ácido fénico al $4 \%$ en agua. La inyección se realizó por goteo o mediante inyección con jeringa. Una vez retirada la piel, los animales fueron conservados por inmersión.

Disección. Luego de retirar la piel, queda expuesta la cara lateral de la región del muslo, la rodilla y porción proximal de la pierna.

A nivel de la región del muslo se observa que el área caudo-lateral está ocupada por el musculo BF, seguido caudalmente por el m. semitendinoso (ST) delimitando ambos el borde caudal de muslo. Un tabique de fascia separa estos músculos entre sí. El primer paso para poder identificar ambas cabezas del BF es seccionar dicho tabique, de manera que los vientres de ambos músculos queden bien separados. Al abordar la celda caudal y separar los músculos BF y ST puede o no observarse sobre el tejido conectivo 
remanente una abundante cantidad de tejido adiposo y la presencia del músculo aductor crural caudal, el mismo se separa fácilmente de los músculos BF y ST.

Dividiendo imaginariamente la región del muslo en tres tercios trabajamos sobre el tercio proximal (cerca de la tuberosidad isquiática). Separado el músculo BF del ST su borde caudal debe revertirse hacia craneal. Al realizar esta acción se podrá apreciar sobre la cara medial del mismo un fino tendón, fácilmente identificable, de aspecto nacarado y débilmente adherido por tejido conectivo laxo al vientre de la cabeza mayor. El mismo puede separarse por divulsión con tijera o utilizando delicadamente un bisturí, hasta aislar su origen en la borde ventro-lateral de la tuberosidad isquiática.

Una vez identificado y aislado el tendón es fácil observar la lámina de tejido conectivo que separa los vientres de ambas cabezas. Dicha capa puede seguirse de manera evidente hasta el tercio distal del músculo, punto a partir del cual se hace mucho menos manifiesto, y donde las fibras de ambos vientres se entremezclan de modo que al continuar la disección distalmente, la separación de las inserciones musculares es artificial.

\section{RESULTADOS}

En todos los casos fue posible poner en evidencia la existencia de dos cabezas de origen para este músculo. Una craneal más importante y superficial y otra caudal, más delgada y ubicada profundamente con respecto a la craneal. La primera se origina en el ligamento sacrotuberal y en la superficie lateral de la tuberosidad isquiática. La cabeza caudal, lo hace en la tuberosidad isquiática (desde su borde ventro-lateral) mediante un delgado tendón que se halló en todas las preparaciones (Fig. 1). Estas partes a pesar de hallarse estrechamente unidas se individualizan a nivel de los vientres musculares por la presencia de una delgada capa de tejido conectivo que se extiende hasta el tercio distal del músculo. La inserción muscular ocurre en forma directa sobre la cara lateral del tercio proximal y la tuberosidad de la tibia. Algunas fibras terminan insertándose en un engrosamiento de la fascia crural, sobre la cara lateral de la pierna. Este engrosamiento aporta una fijación directa sobre el tendón calcáneo común al cual contribuye.

La inervación de ambas cabezas proviene de ramos musculares del nervio isquiático. Este nervio recorre la cara medial del BF y envía entre dos y tres ramos que penetran en el vientre muscular. El nervio glúteo caudal no destina ramos para la inervación del músculo BF.

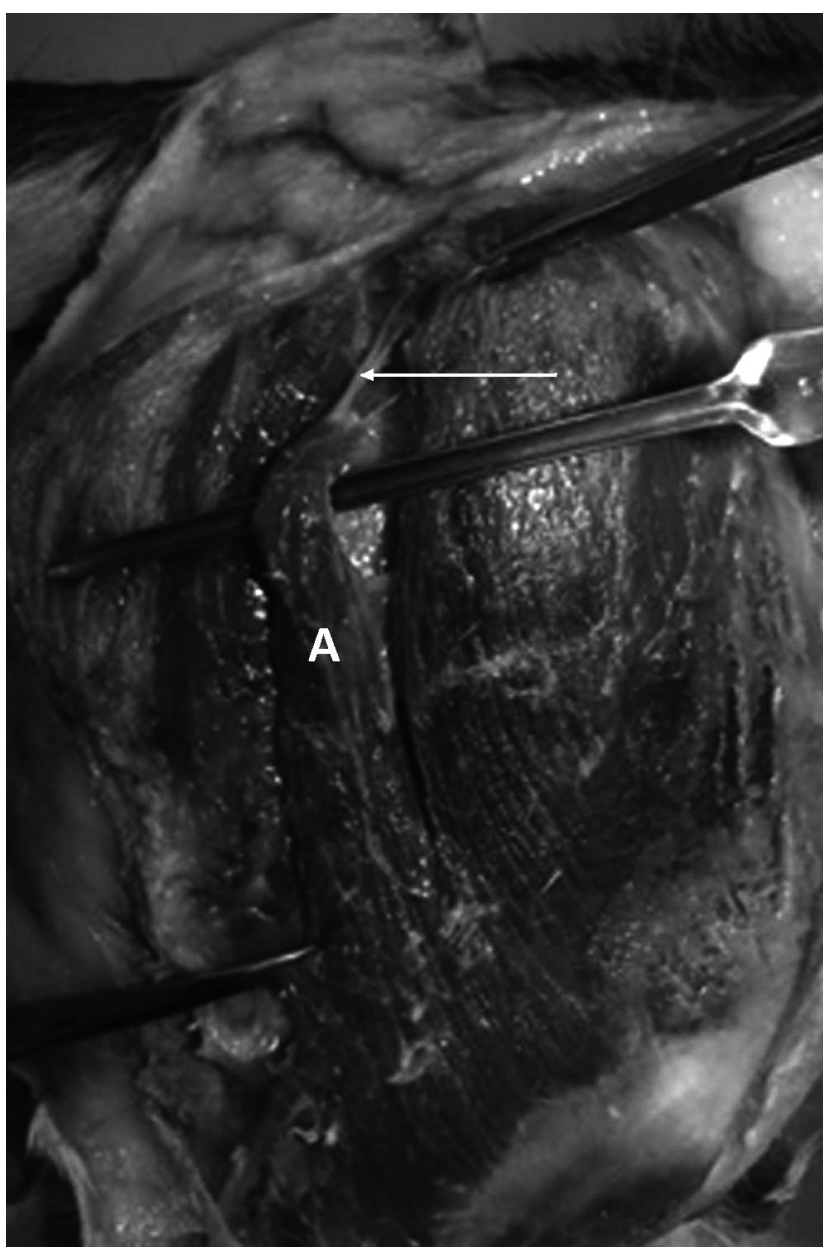

Fig. 1. Vista lateral de la disección del muslo izquierdo del canino. Se ha separado la cabeza caudal del m. bíceps (A) su delgado tendón de origen se identifica claramente en todas las preparaciones (flecha).

\section{DISCUSIÓN}

La presencia de dos cabezas de origen en el BF en el canino es motivo de controversias ente los autores considerados clásicos. Es así como describen su existencia Grassé (1958), Evans (1993) y Getty (1984); mientras que Schaller (1996) no las menciona, pero cita dos orígenes. Finalmente, Barone (1996) dice que en los mamíferos domésticos no existen dos cabezas para este músculo pero en la descripción del BF del canino menciona "una parte accesoria (del origen) más delgada y profunda que contornea el borde caudal y se expande antes de perderse sobre la región de la rodilla".

Nosotros encontramos que esta cabeza más pequeña puede disecarse con facilidad del vientre principal casi hasta la inserción sobre el tercio proximal de la tibia en todos 
los casos estudiados. Proponemos aceptar entonces la existencia de dos cabezas para el BF del canino una craneal más superficial y voluminosa y otra caudal más pequeña y profunda.

ARZONE, C.A.; BLANCO, C. J.; GENOUD, P.; PELLEGRINO, F. C.; SÁNCHEZ, G. \& VIDAL FIGUEREDO, R. J. Anatomical review of canine biceps femoris muscle. Int. J. Morphol., 28(4):1147-1149, 2010.

SUMMARY: The biceps femoris (BF) muscle plays a fundamental role in the biomechanics of the canine pelvic limb, acting in flexion - extension on knee articulation and abduction of the limb. Correct evaluation plays an important role in veterinary clinic. There are controversial issues among the authors consulted about the morphology of this muscle. The present study aims to discuss the various descriptions proposed for this muscle, considering insertions, structure and innervation. Bilateral dissections of 12 animals were carried out. Pieces conservation was done by immersion in pools with $10 \%$ formaldehyde and $4 \%$ carbolic acid in water. Different techniques were used in order to achieve various observations of muscle structures. It was found that BF muscle originates by two heads, as is implicit in its name, a craneal head, bulkier and a smaller caudal head. The first takes origin in the sacrotuberal ligament and the lateral surface of the ischial tuberosity. The caudal head, originates from the ischial tuberosity. These parts are closely linked but they can be identified at the level of the muscle bellies through a thin layer of connective tissue that extends to the distal part of the muscle. Regarding the innervation, we found that no caudal gluteal nerve branches reach this muscle.

KEY WORDS: Biceps femoris muscle; Canine; Anatomical structure.

\section{REFERENCIAS BIBLIOGRÁFICAS}

Barone, R. Anatomie Comparée des Mammifères Domestiques, Arthrologie Myologie. Vigot, París, 1996. pp.8779.

Dyce, K. M.; Sack, W. O. \& Wensing, C. J. G. Anatomía Veterinaria. $2^{\mathrm{a}}$ ed. Madrid, McGraw-Hill Interamericana, 1999.

Evans, H. E. Miller's anatomy of the dog. Philadelphia, Saunders, 1993.

Getty, R. Anatomía de los animales domésticos de Sisson y Grossman. Barcelona, Salvat, 1984.

Grassé, P. P. Traité de zoologie, anatomie systematique, biologie. París, Masson, 1958.

Schaller, O. Nómina Anatómica Veterinaria Ilustrada. Zaragoza, Ed. Acribia, 1996.

Schwarze, E.; Schröder, L. \& Michel, G. Compendio de Anatomía Veterinaria. Zaragoza, Acribia, 1970.

\author{
Dirección para correspondencia: \\ Dr. Carlos Arzone \\ Cátedra de Anatomía \\ Facultad de Ciencias Veterinarias \\ Avda. Chorroarin 280 \\ C1427CWO \\ Universidad de Buenos Aires \\ ARGENTINA
}

Email: carzone@fvet.uba.ar

Recibido : 12-07-2010

Aceptado: 06-09-2010 
